\title{
Characterization of Stowaway MITEs in pea (Pisum sativum L.) and identification of their potential master elements
}

\author{
Jiří Macas, Andrea Koblížková, and Pavel Neumann
}

\begin{abstract}
We have investigated miniature inverted-repeat transposable elements (MITEs) of the Stowaway family and corresponding Mariner-like master elements that could potentially facilitate their mobilization in the genome of the garden pea (Pisum sativum L.). The population of pea Stowaway MITEs consists of $10^{3}-10^{4}$ copies dispersed in the genome. Judging from a sequence analysis of 17 isolated Stowaway elements and their flanking genomic regions, the elements are relatively uniform in size and sequence and occur in the vicinity of genes as well as within repetitive sequences. Insertional polymorphism of several elements was detected among various Pisum accessions, suggesting they were still transpositionally active during diversification of these taxa. The identification of several Mariner-like elements (MLEs) harboring intact open reading frames, capable of encoding a transposase, further supports a recent mobilization of the Stowaway elements. Using transposase-coding sequences as a hybridization probe, we estimated that there are about 50 MLE sequences in the pea genome. Among the 5 elements sequenced, 3 distinct subfamilies showing mutual similarities within their transposase-coding regions, but otherwise diverged in sequence, were distinguished and designated as Psmar-1 to Psmar-3. The terminal inverted repeats (TIRs) of these MLE subfamilies differed in their homology to the TIRs of Stowaway MITEs. The homlogy ranged from 9 bp in Psmar-3 to 30 bp in Psmar-1, which corresponds to the complete Stowaway TIR sequence. Based on this feature, the Psmar-1 elements are believed to be the most likely candidates for the master elements of the Stowaway MITEs in pea.
\end{abstract}

Key words: Mariner-like transposons, master elements, Stowaway MITEs, insertional polymorphism, Pisum sativum.

Résumé : Les auteurs ont étudié les transposons MITE ( «miniature inverted-repeat transposable elements ») de la famille Stowaway et les éléments autonomes correspondants de type Mariner, lesquels pourraient potentiellement causer la mobilité de ces éléments chez le petit pois (Pisum sativum L.). Le génome du pois compte $10^{3}-10^{4}$ copies dispersées de MITE Stowaway. L'analyse de la séquence de 17 éléments Stowaway et de l'ADN génomique qui les borde a révélé que ceux-ci sont relativement uniformes tant en matière de taille que de séquence et qu'ils sont situés à la fois à proximité de gènes et au sein de séquences répétées. Du polymorphisme insertionnel pour plusieurs éléments a été détecté parmi diverses accessions de Pisum, ce qui suggère qu'ils étaient encore mobiles lors de la différenciation de ces taxons. L'identification de plusieurs éléments de type Mariner (MLE, «Mariner-like elements ») ayant des cadres de lecture ouverts intacts, capables de coder pour une transposase, vient appuyer davantage l'hypothèse d'une récente mobilité de ces éléments Stowaway. En employant la séquence codant pour la transposase comme sonde, les auteurs estiment qu'il y aurait environ 50 séquences MLE au sein du génome du pois. Parmi les 5 éléments séquencés, 3 sousfamilles distinctes montrant des similitudes au sein des régions codant pour la transposase, mais autrement assez divergentes, ont été observées et appelées Psmar-1 à Psmar-3. Les répétitions terminales inversées (TIR) de ces sousfamilles de MLE présentaient différents degrés d'homologie avec les TIR des MITE Stowaway. L'homologie variait entre 9 pb chez Psmar-3 et 30 pb chez Psmar-1, ce qui, dans ce dernier cas, correspond à la séquence complète du TIR de Stowaway. Sur cette base, les éléments Psmar-1 sont considérés comme étant les meilleurs candidats à titre d'éléments autonomes des MITE Stowaway chez le pois.

Mots clés : transposons de type Mariner, éléments autonomes, MITE Stowaway, polymorphisme insertionnel, Pisum sativum.

[Traduit par la Rédaction]

Received 15 December 2004. Accepted 7 May 2005.

Published on the NRC Research Press Web site at

http://genome.nrc.ca on 19 October 2005.

Corresponding Editor: T.B. Bureau.

J. Macas, ${ }^{1}$ A. Koblížková, and P. Neumann. Institute of Plant Molecular Biology, Laboratory of Molecular Cytogenetics, Branišovská 31, České Budějovice, CZ-37005 Czech Republic.

${ }^{1}$ Corresponding author (e-mail: macas@umbr.cas.cz).

\section{Introduction}

Nuclear genomes of the majority of higher plants are predominantly composed of numerous families of repetitive elements differing in their origin, genomic organization, and nucleotide sequences. Among these families, mobile elements (also called transposons) often represent the most abundant fraction (Kumar et al. 1997; SanMiguel and Bennetzen 1998; Neumann et al. 2001). This is mainly due to the accumulation of retrotransposons, elements that spread 
through the genome via a copy-and-paste mechanism involving RNA intermediate (Bennetzen 2000). The other class of mobile elements, called DNA transposons, move within genomes using an excision-reintegration (cut-and-paste) mechanism and are therefore only moderately abundant. DNA transposons are characterized by the presence of terminal inverted repeats (TIRs) at their ends and, in the case of autonomous elements, by encoding a transposase, which facilitates their mobilization (reviewed in Galun 2003). Structurally distinct mobile elements that share some features with DNA transposons but are small and lack any coding capacity are called miniature inverted-repeat transposable elements (MITEs). First discovered in maize (Bureau and Wessler 1992), a number of MITEs distinguished by their nucleotide sequences were later identified in both monocot and dicot plants and also in animals (Feschotte et al. 2002a; Feschotte et al. 2002b). In contrast with other DNA transposons, MITEs occur in high copy numbers in plant genomes, reaching up to $10^{4}$ copies per haploid genome (Bureau and Wessler 1992; Mao et al. 2000; Zhang et al. 2000). Recent progress in sequencing and computer analysis resulted in the classification of the majority of MITEs as nonautonomous deletion derivatives of longer DNA transposons belonging to either of the 2 main superfamilies, Tc1/Mariner and PIF/ Harbinger (Feschotte et al. 2002b). This classification is based on sequence similarities of the TIRs and target site duplications (TSDs) of MITEs and respective DNA transposons, which reflect their mobilization by the same transposases encoded by the full-length DNA transposons (also called "master elements").

Stowaway elements (Bureau and Wessler 1994) rank among the most abundant plant MITEs in terms of both their distribution in various plants taxa and their copy numbers in individual plant species (Bureau and Wessler 1994; Mao et al. 2000; Feschotte et al. 2002b; Feschotte et al. 2003). In the genome, Stowaway elements occur in close association with genes (Mao et al. 2000), which makes them ideal for designing molecular markers that target coding sequences. Stowaway elements are defined by having TIRs that include a 10-bp consensus sequence (5'-CTCCCTCCRT-3') and by generating TSD of the dinucleotide TA (Bureau and Wessler 1994; Feschotte et al. 2003). These features led to their association with the Tc1/Mariner superfamily of transposons (Feschotte et al. 2002b), more specifically with the group of Mariner-like elements (MLEs) (Feschotte et al. 2003). Although PCR-based detection of conserved domains coding for Mariner-like transposases revealed their presence in a wide range of plants (Feschotte and Wessler 2002), the fulllength Mariner-like transposons that could act as master elements for Stowaway MITEs have been isolated from only soybean and rice (Jarvik and Lark 1998; Feschotte et al. 2003). Similarly, a comprehensive characterization of Stowaway elements is available for only a small number of extensively sequenced plant genomes, whereas information from other species is absent or very limited.

As part of our investigation of repetitive sequences present in the pea genome (Pisum sativum L.) we aimed to characterize the population of Stowaway MITEs. Owing to relatively limited amounts of sequence data from this species, only 3 copies of Stowaway have previously been identified using computer analysis of pea DNA sequences (Bureau and Wessler 1994; Macas et al. 2003). Thus, to investigate the sequence diversity of these elements, we cloned and sequenced additional copies and characterized the abundance and insertional polymorphisms of Stowaway MITEs in selected taxa of pea. Moreover, we isolated and sequenced several full-length or partial Mariner-like elements, the potential "masters" of Stowaway MITEs. We analyzed these elements with respect to their structure, coding capacity, and eventual association with the Stowaway MITEs.

\section{Materials and methods}

\section{Plant material and genomic DNA isolation}

Seeds of plant species used in this study were obtained from the Plant Breeding Station at Borsov, Czech Republic (Pisum sativum L. 'Carrera'), and the Western Regional Plant Introduction Station, Pullman, Washington, USA (Pisum sativum subsp. sativum (accession number PI116056), Pisum sativum subsp. asiaticum Govor. (W615036), Pisum sativum var. arvense (L.) Poir. (PI268480), Pisum fulvum Sm. (PI560063), Pisum sativum subsp. elatius (Steven ex M. Bieb.) Meikle (W615043), Pisum sativum var. elatius (Steven ex M. Bieb.) Meikle (W616220), Pisum sativum subsp. abyssinicum (A. Braun) Govor. (PI358610), Pisum sativum subsp. transcaucasicum Govor. (W612704), and Pisum sativum var. pumilio Meikle (PI560068)). Total genomic DNA was extracted from leaves pooled from 4-5 plants as described by Dellaporta et al. (1983). All DNA concentration measurements were done using the PicoGreen dye (Molecular Probes, Eugene, Oregon, USA) according to the manufacturer's recommendations.

\section{Cloning of Stowaway and Mariner-like elements}

The "shotgun" genomic library was prepared from $P$. sativum 'Carrera' DNA subjected to sonication, mung bean nuclease treatment, and size fractionation on an agarose gel. The fragments of about 700-1000 bp were purified from the gel, treated with polynucleotide kinase in the presence of ATP, and cloned into SmaI-cut and dephosphorylated plasmid vector (pBluescript II SK+; Stratagene, La Jolla, Oregon, USA). The library was screened by colony hybridization with the probe prepared by PCR using primers TIR1 (5'-CCT CCG TTC CAT TTT AAG TGT C-3') and TIR2 (5'-TTA CTT CCT CTG TTC CTT T-3') designed according to TIR sequences of 3 known pea Stowaway elements (Stow-Psl Stow-Ps3, Table 1) and $P$. sativum genomic DNA as a template. PCR was performed in $50 \mu \mathrm{L}$ of reaction mix consisting of $1 \times$ PCR buffer, $1.5 \mathrm{mmol} \mathrm{MgCl}_{2} / \mathrm{L}, 0.2 \mathrm{mmol}$ dNTPs/L, $0.2 \mu \mathrm{mol}$ primers/L, $2.5 \mathrm{U}$ of Taq polymerase (Promega, Madison, Wisconsin, USA), and $20 \mathrm{ng}$ of template DNA. The reaction involved 30 cycles of $94{ }^{\circ} \mathrm{C}$ for $1 \mathrm{~min}, 50{ }^{\circ} \mathrm{C}$ for $1 \mathrm{~min}$, and $72{ }^{\circ} \mathrm{C}$ for $1 \mathrm{~min}$. PCR was preceded by an initial denaturation $\left(94{ }^{\circ} \mathrm{C}\right.$ for $\left.2 \mathrm{~min}\right)$ and followed by a final extension step $\left(72{ }^{\circ} \mathrm{C}\right.$ for $\left.10 \mathrm{~min}\right)$. The reaction products were labeled and hybridized using the AlkPhos Direct ${ }^{\mathrm{TM}}$ hybridization and detection kit (Amersham Biosciences, Freiburg, Germany). Probe detection was performed using CDP-Star ${ }^{\circledR}$ substrate (Amersham Biosciences) and the signals were captured on X-ray film. In addition to the short-insert "shotgun" library, the pea genomic library cloned into a phage vector (Lambda DASH II, Stratagene) 
Table 1. Stowaway elements identified in the pea genome. TSD, target site duplication.

\begin{tabular}{|c|c|c|c|c|c|c|c|}
\hline $\begin{array}{l}\text { Element } \\
\text { name }\end{array}$ & $\begin{array}{l}\text { Length } \\
\text { (bp) }\end{array}$ & $\operatorname{TSD}\left(5^{\prime} / 3^{\prime}\right)^{a}$ & Clone name ${ }^{b}$ & $\begin{array}{l}\text { Length } \\
\text { (bp) }\end{array}$ & $\begin{array}{l}\text { GenBank } \\
\text { accession }\end{array}$ & $\begin{array}{l}\text { Element } \\
\text { position }\end{array}$ & Notes \\
\hline Stow-Ps1 & 275 & $\mathrm{cA} / \mathrm{Tt}$ & PEALCTN & 3881 & L11745 & $1548-1274$ & $\begin{array}{l}\text { Identified by Bureau and Wessler (1994) in } 5^{\prime} \\
\text { flanking region of lectin gene }\end{array}$ \\
\hline Stow-Ps2 & 274 & $\mathrm{cc} / \mathrm{TA}$ & PEACAB 80 & 1993 & K02067 & $123-396$ & $\begin{array}{l}\text { Identified by Bureau and Wessler (1994) in } 5^{\prime} \\
\text { flanking region of CAB binding protein gene }\end{array}$ \\
\hline Stow-Ps3 & 275 & $\mathrm{TA} / \mathrm{aA}$ & CYP73A9-v1 & 4090 & AF175275 & $1901-2175$ & $\begin{array}{l}\text { Identified by Macas et al. (2003) in intron of } \\
\text { trans-cinnamic acid hydroxylase gene }\end{array}$ \\
\hline Stow-Ps5 & & 一/TA & $\mathrm{c} 190$ & 1341 & AY833537 & $1-206^{c}$ & - \\
\hline Stow-Ps6 & & 一/TA & c229 & 904 & AY833538 & $1-155^{c}$ & - \\
\hline Stow-Ps 7 & 270 & TA/TA & $\mathrm{c} 231$ & 1000 & AY833539 & $389-658$ & - \\
\hline Stow-Ps 8 & & —/TA & $\mathrm{c} 232$ & 524 & AY833540 & $1-196^{c}$ & - \\
\hline Stow-Ps9 & 275 & TA/TA & $\mathrm{c} 233$ & 572 & AY833541 & $296-570$ & - \\
\hline Stow-Ps10 & & —/Unknown & $\mathrm{c} 234$ & 950 & AY833542 & $1-266^{c}$ & $\begin{array}{l}\text { Right TIR not identified owing to sequence } \\
\text { rearrangements (duplication/inversion) in } \\
\text { this region. }\end{array}$ \\
\hline Stow-Ps 12 & 274 & TA/TA & c239 & 1566 & AY833544 & $989-1262$ & - \\
\hline Stow-Ps 13 & 274 & TA/TA & $c 242 b$ & 1626 & AY833545 & $137-410$ & - \\
\hline Stow-Ps 14 & 274 & TA/TA & c243 & 1250 & AY833546 & $127-400$ & - \\
\hline Stow-Ps 15 & 274 & TA/TA & c246 & 1501 & AY833547 & $233-506$ & - \\
\hline Stow-Ps16 & 273 & TA/TA & $\mathrm{c} 247$ & 1268 & AY833548 & $\begin{array}{r}368-508+ \\
785-917\end{array}$ & Contains insertion of Stow-Ps17 \\
\hline Stow-Ps17 & 274 & TA/TA & $\mathrm{c} 247$ & 1268 & AY833548 & $509-782$ & - \\
\hline
\end{tabular}

${ }^{a}$ Two nucleotides flanking $5^{\prime}$ and $3^{\prime}$ element ends, respectively, are shown. Sequences differing from the consensus TSD (TA/TA) are in lowercase.

${ }^{b}$ In the cases of previously reported sequences (Stow-Ps1 to Stow-Ps3) GenBank loci names are shown.

${ }^{c}$ Element truncated because of the cloning.

was screened with the same probe and positive clones were purified as described earlier (Macas et al. 2003).

A hybridization probe specific for Mariner-like elements was prepared by PCR amplification of $50 \mathrm{ng}$ of pea genomic DNA using the primers MLE3A and MLE5A (Feschotte and Wessler 2002). The reaction was performed in $50 \mu \mathrm{L}$ of $1 \times$ PCR buffer, $2.0 \mathrm{mmol} \mathrm{MgCl}_{2} / \mathrm{L}, 0.2 \mathrm{mmol} \mathrm{dNTPs} / \mathrm{L}$, $0.2 \mu \mathrm{mol}$ primers/L, $2.5 \mathrm{U}$ of Platinum ${ }^{\circledR}$ Taq polymerase (Invitrogen, Carlsbad, California, USA), employing 35 cycles of the same temperature profile as described earlier, except for the annealing at $45^{\circ} \mathrm{C}$. The reaction products were cloned using TOPO TA Cloning ${ }^{\circledR}$ Kit (Invitrogen) and sequenced to verify amplification of the desired sequences. Equimolar amounts of the DNA from 3 of these clones (GenBank accessions AY833533-AY833535) were mixed and used for probe preparation and library screening as described earlier.

\section{Sequencing and computer analysis}

Positive clones identified by colony or plaque-lift hybridizations were sequenced using the dideoxy chain termination method (Sanger et al. 1977) either directly (short-insert plasmid clones) or following subcloning of selected restriction fragments (phage clones). In the case of subclones longer than 700-800 bp, the sequencing templates were generated using GeneJumper ${ }^{\mathrm{TM}}$ Primer Insertion Kit (Invitrogen). Sequence assembly and basic analysis were done with Staden Package software (Staden et al. 1996) and program tools implemented at the Biology WorkBench website (http://workbench.sdsc.edu/). Stowaway and Mariner-like elements and their surrounding regions were then tested for homology to other plant sequences using BLAST (Altschul et al. 1997), FASTA (Pearson and Lipman 1988), and Dotter (Sonnhammer and Durbin 1995). Homology searches in new GenBank entries using BLAST and FASTA were periodically repeated until October 2004. Multiple sequence alignments were performed using ClustalW (Thompson et al. 1994) and similarities within the alignments were visualized employing Boxshade (created by K. Hofmann and M.D. Baron) and WebLogo (Schneider and Stephens 1990; Crooks et al. 2004) programs.

\section{Characterization of abundance, genomic organization, and insertional polymorphism}

To estimate the copy number of Stowaway elements in the pea genome, serial dilutions of genomic DNA were quantitatively dot-blotted on Hybond ${ }^{\mathrm{TM}} \mathrm{N}+$ membrane (Amersham Biosciences) together with a cloned fragment containing the Stow-Ps3 element as a hybridization standard. The quantity of spotted genomic DNA corresponding to $10^{3}$ to $10^{5}$ copies of the haploid genome (1C) was compared with $10^{6}$ to $5 \times 10^{9}$ copies of the hybridization standard. Dot blots were hybridized with the probe that was prepared by PCR using TIR1 and TIR2 primers as described earlier. The probe was labeled and hybridized as described for library screening. The hybridization and washing temperatures were varied from 45 to $55{ }^{\circ} \mathrm{C}$ to achieve moderate or high stringency. Alternatively, estimation of copy numbers for both Stowaway and Mariner-like elements were done based on the number of positive phage clones observed after the screening with the 
respective probes, taking into account the pea genome size (1C $=4337$ Mbp; Baranyi and Greilhuber 1996) and average insert size in the library (15 kbp).

Southern blots of the pea genomic DNA were prepared by running $2 \mu \mathrm{g}$ aliquots digested with various restriction endonucleases on $1 \%$ or $2 \%$ agarose gels and blotting to Hybond $\mathrm{N}+$ membrane. The blots were hybridized using the AlkPhos Kit, as described earlier, using hybridization and a washing temperature of $50{ }^{\circ} \mathrm{C}$.

Screening for insertional polymorphisms of Stowaway elements in various pea accessions was performed using $20 \mathrm{ng}$ of genomic DNA as a template in $30 \mu \mathrm{L}$ reactions composed of $1 \times$ PCR buffer, $0.2 \mathrm{mmol} \mathrm{dNTPs} / \mathrm{L}, 1.5 \mathrm{mmol} \mathrm{MgCl}_{2} / \mathrm{L}$, $0.2 \mu \mathrm{mol}$ primers/L, and 1.2 U of Platinum Taq polymerase. Primer pairs used for amplification of individual loci are given in Table 2 . The PCR was performed for 30 cycles of $94{ }^{\circ} \mathrm{C}$ for $1 \mathrm{~min}, 55^{\circ} \mathrm{C}$ for $1 \mathrm{~min}$, and $72{ }^{\circ} \mathrm{C}$ for $2 \mathrm{~min}$. The reaction was preceded by an initial denaturation $\left(94^{\circ} \mathrm{C}\right.$ for $2 \mathrm{~min})$ and followed by a final extension step $\left(72{ }^{\circ} \mathrm{C}\right.$ for $10 \mathrm{~min})$. The amplification products were resolved by ethidium bromide-stained $2 \%$ agarose gel electrophoresis.

\section{Results}

\section{Isolation and characterization of Stowaway elements}

To isolate additional copies of pea Stowaway elements, PCR primers were designed based on conserved terminal sequences of the 3 previously identified elements (Stow-Ps 1 , Stow-Ps2, and Stow-Ps3, Table 1). PCRs, using pea genomic DNA as a template, amplified fragments of expected length (about $250 \mathrm{bp}$, data not shown), which were used as a probe to screen pea genomic libraries cloned into plasmid or phage vectors. Among 24500 plasmid and 20700 phage clones subjected to screening, 8 and 94, respectively, gave positive hybridization signals. These numbers indicated that there are about 1500 copies of Stowaway elements per haploid pea genome. This estimate was also confirmed using quantitative dot-blot hybridization of serial dilutions of genomic DNA, which produced signals equivalent to 1000-10 000 element copies (supplementary material, Fig. S12). Thirteen randomly picked positive clones were sequenced and analyzed, yielding a total of 14 element sequences (Table 1). Except for 4 elements truncated because of the cloning process, all MITEs were 270-274 bp in length and the majority of them were flanked by a duplication of their integration site (dinucleotide TA). One clone (c247, accession No. AY833548) contained 2 copies of elements, with 1 element nested into another, and both of them surrounded by TSDs. Multiple alignment of all newly identified and the 3 previously described pea Stowaway sequences revealed their relative homogeneity (78\%-98\% nucleotide similarity between fulllength elements) and the presence of 30-bp TIRs (Figs. 1 and 4A). The terminal parts of TIRs included a 10-bp signature motif (5'-CTCCCTCCGT-3') typical for Stowaway elements. Southern hybridization of the Stowaway probe to pea genomic DNA digested with various restriction endonuc- leases produced mainly a continuous smear indicative of dispersed genomic organization of these sequences (Fig. 2).

\section{Analysis of adjacent genomic sequences}

We characterized the insertion sites of pea Stowaway MITEs by investigating the sequences of genomic regions surrounding the elements. Similarity searches of these regions were performed against known plant sequences (Table 2). In many cases, no detectable homologies or homologies to only poorly annotated entries prevented unambiguous classification of the surrounding sequences. However, there were at least 2 elements (Stow-Ps4 and Stow-Ps10) located within putative gene encoding regions. Stow-Ps4 was inserted within the intron of a gene sequence with high similarity to translation elongation factor genes and expressed sequence tags (ESTs) from several plant species. The sequences adjacent to Stow-Ps10 were classified as potentially coding based on their homology to ESTs and predicted exon sequences from Lupinus and Medicago. On the other hand, we found insertion sites of 2 other elements (Stow-Ps6 and Stow-Ps 12) were located within repetitive sequences of retroelement origin. There were also instances (e.g., StowPs8, Stow-Ps11) of significant similarities to GenBank accessions annotated as gene sequences but limited to intergenic regions that were due to our analysis containing repetitive elements.

\section{Insertional polymorphism}

The presence of Stowaway elements in respective genomic loci was tested for a total of 9 accessions (subspecies or cultivars) of $P$. sativum and $P$. fulvum. Primer pairs were designed according to 7 genomic sequences carrying element insertions identified in this study and also according to the element Stow-Ps3 described in our previous work (Table 2). Three tested loci produced single bands in all accessions (Stow-Ps4, Stow-Ps7, and Stow-Ps15, data not shown); the band sizes corresponded to the size expected if the Stowaway element was present in these regions. Amplification of Stow-Ps 11 insertion site yielded fragments corresponding to the locus lacking the element in all accessions; however, 3 accessions yielded additional fragments of the size indicating the presence of the element (supplementary material, Fig. S2 ${ }^{2}$ ). A typical insertional polymorphism was observed in the case of Stow-Ps3 where each accession produced a single band corresponding to the locus either with or without the Stowaway element (Fig. 3A). This was also verified by cloning and sequencing the PCR products shown in the lanes $1,3,4,5,9$, and 10 . In all cases where the element was absent, there was no footprint detectable in the sequence, suggesting the element had never inserted into these loci (supplementary material, Fig. $\mathrm{S}^{2}$ ). An interesting and highly polymorphic amplification pattern was observed in the case of Stow-Ps16 + Stow-Ps17, which included 3 fragment sizes corresponding to the presence of 2,1 , or no element (Fig. 3B).

\footnotetext{
${ }^{2}$ Supplementary data for this article are available on the Web site or may be purchased from the Depository of Unpublished Data, Document Delivery, CISTI, National Research Council Canada, Ottawa, ON K1A 0R6, Canada. DUD 4016. For more information on obtaining material refer to http://cisti-icist.nrc-cnrc.gc.ca/irm/unpub_e.shtml.
} 
Table 2. Flanking genomic sequences and insertional polymorphism of Stowaway elements.

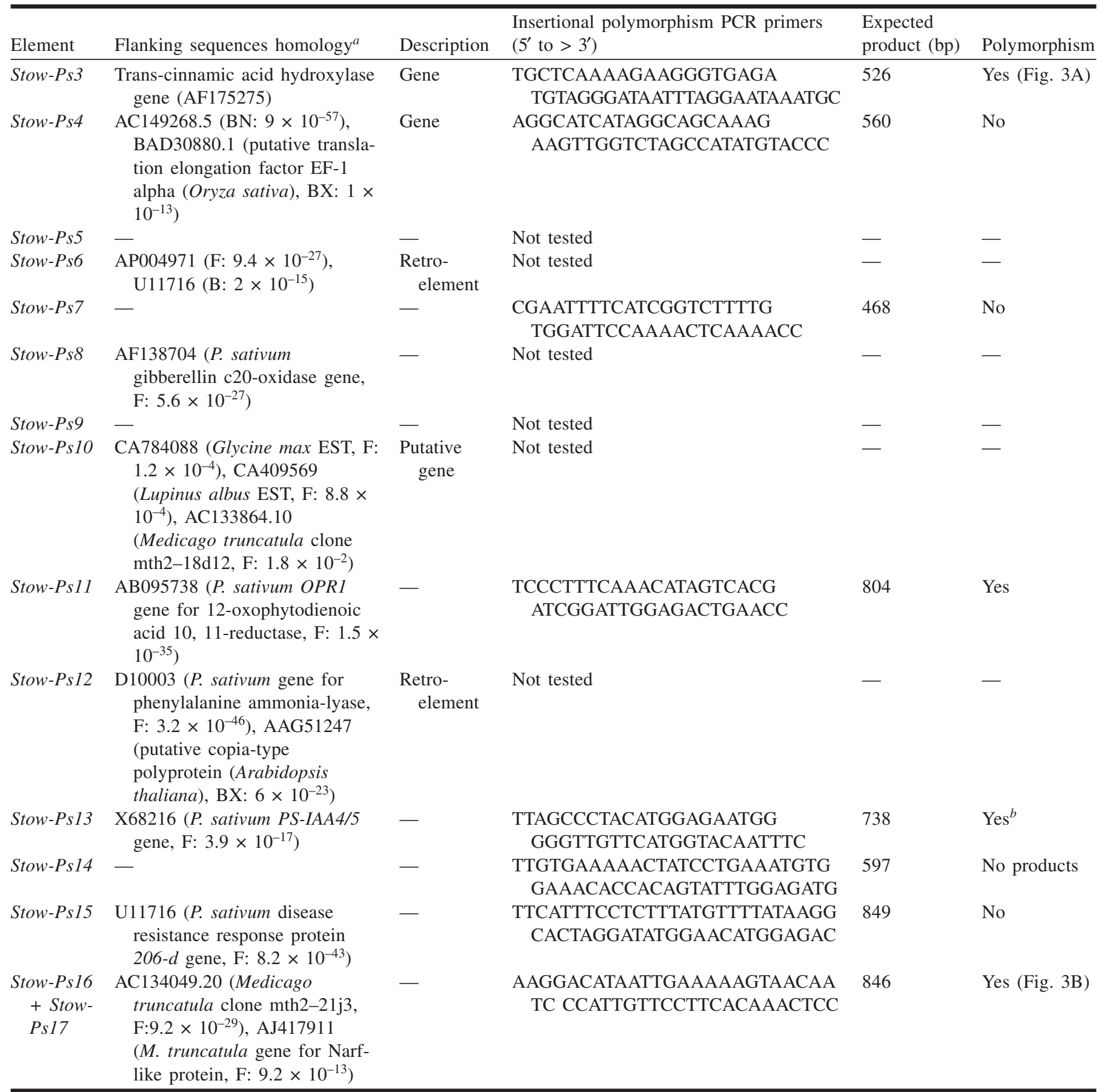

${ }^{a}$ Accession numbers of sequences displaying the best homologies are shown. The programs used to detect the homology (F, Fasta; BN, BlastN; BX, BlastX) and the score are given in parentheses.

${ }^{b}$ No amplification products appear in the majority of accessions.

\section{Identification and characterization of putative master elements}

Primers designed according to conserved regions of Mariner-like transposases (Feschotte and Wessler 2002) were used in PCR to test occurrence of corresponding sequences in the pea genome. The reaction resulted in amplification of fragments approximately $380 \mathrm{bp}$ in length, appearing as a single band on agarose gel electrophoresis. Cloning and sequencing of 3 randomly picked fragments (GenBank accessions AY833533-AY833535) revealed that their nucleotide sequences were highly similar (70\%-87\% mutual similarities) and displayed significant homologies to known plant MLE transposases. Moreover, each could be translated as a single open reading frame (no stop codons present) and 
Fig. 1. Sequence logo showing conservation of nucleotides within pea Stowaway elements. The logo was created using the method of Schneider and Stephens (1990) as implemented on the WebLogo server (Crooks et al. 2004) and it is based on multiple sequence alignment of elements listed in Table 1. The alignment is available from the EMBL_Align database under accession number ALIGN_000801.

\section{:

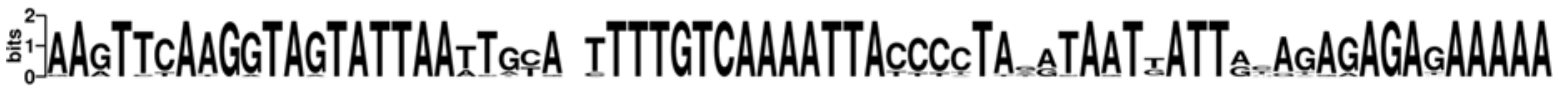

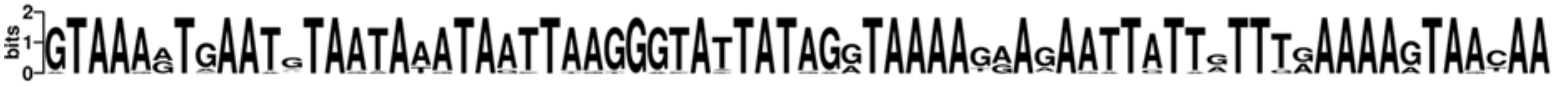

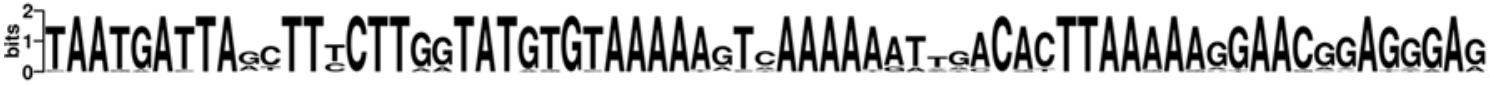

Fig. 2. Southern blot of pea genomic DNA digested with RsaI (lane 1), MseI (lane 2), DraI (lane 3), EcoRI (lane 4), EcoRV (lane 5), BglII (lane 6), and XbaI (lane 7), and hybridized with the probe specific for Stowaway sequences. Restriction digests were resolved on 2\% (lanes 1-3) or 1\% (lanes 4-7) agarose gels. Restriction fragment lengths are indicated separately for lanes 13 (left) and 4-7 (right).

(kb)
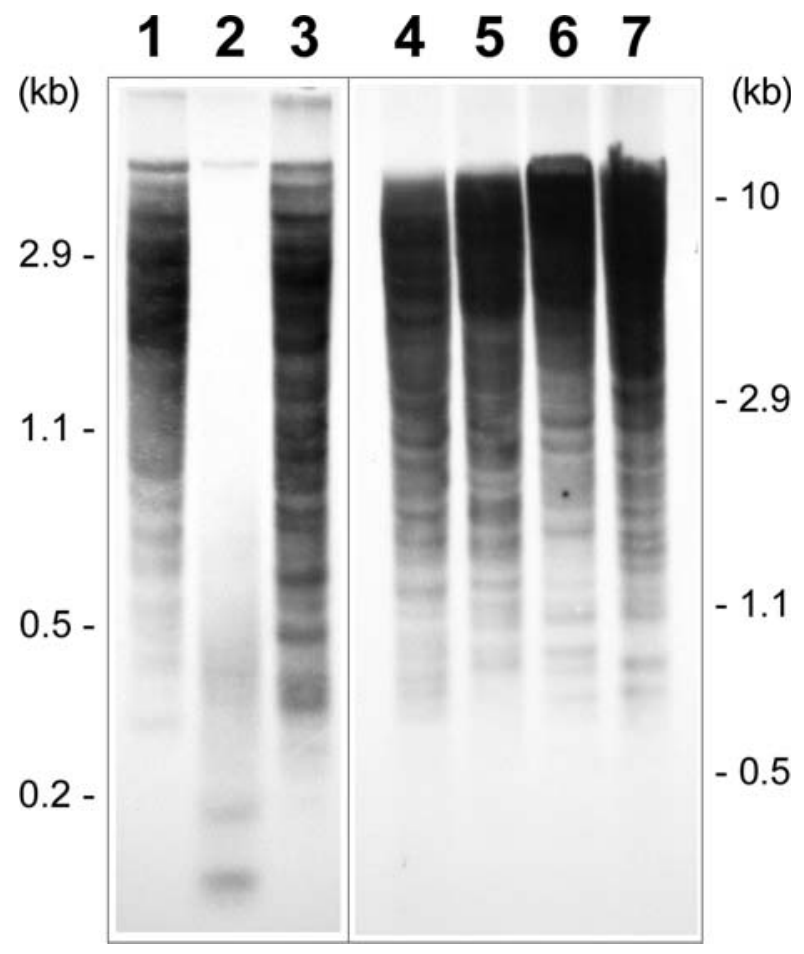

their deduced protein sequences confirmed their assignment as parts of the MLE coding sequences. Using the PCRamplified fragments as a probe, the pea genomic libraries were screened to identify and sequence full-length elements. Among 150000 phage clones screened, 29 gave positive hybridization signals, which corresponds to the presence of 53 MLE sequences per haploid pea genome. Five positive clones were subcloned and the corresponding elements were either partially or completely sequenced (Table 3). Two almost identical full-length Mariner-like elements were identified and because of their high similarity (99\% over their entire length) were designated Psmar-1A and Psmar-1B. The
Fig. 3. Examples of insertional polymorphism of Stowaway elements. Primer pairs derived from sequences surrounding StowPs3 (A) and Stow-Ps16 + Stow-Ps17 (B) insertion sites were used to amplify corresponding loci from $P$. sativum 'Carrera' (lane 1), P. sativum subsp. sativum (lane 2), P. sativum subsp. elatius (lane 3 ), $P$. sativum var. elatius (lane 4$), P$. sativum var. arvense (lane 5), $P$. sativum var. pumilio (lane 6), $P$. sativum subsp. abyssinicum (lane 7), $P$. sativum subsp. transcaucasicum (lane 8), P. sativum subsp. asiaticum (lane 9), and P. fulvum (lane 10). Lane 11 contains a PCR with no template (negative control). The amplification products were resolved on ethidium bromide-stained $2 \%$ agarose gels.

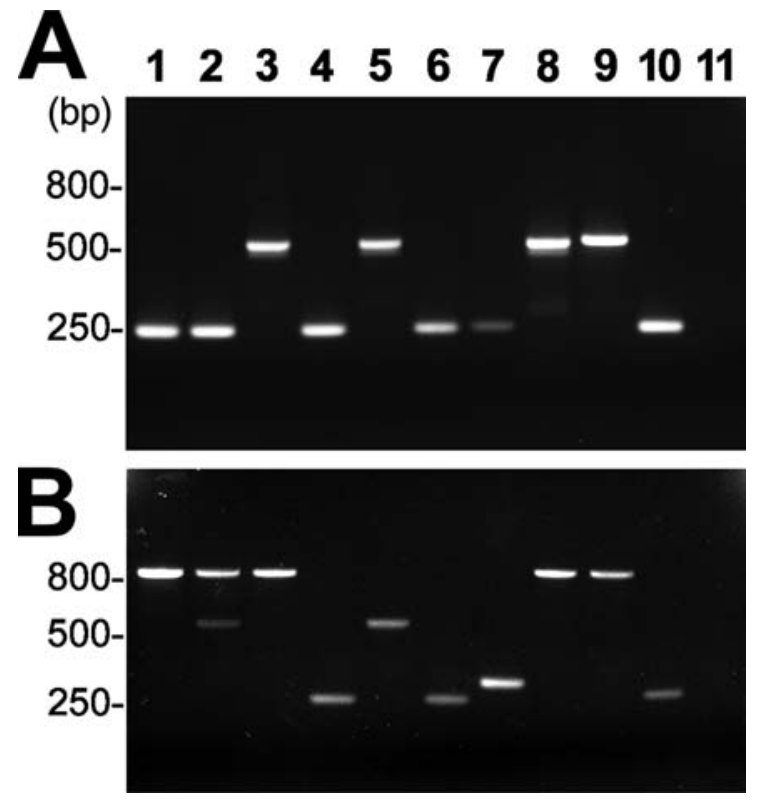

elements Psmar-1A and Psmar-1B were 3204 and 3201 bp, respectively, and were inserted into unrelated genomic sequences. Their terminal inverted repeats included 31 nucleotides.; in addition to this, the right TIRs included a 22-bp duplication. The terminal regions also displayed similarity to the TIRs of pea Stowaway MITEs, which spanned $30 \mathrm{bp}$ (Fig. 4A). Both Psmar-1A and Psmar-1B elements harbor putative coding sequence of 1236 nucleotides uninterrupted by stop codons, thus potentially coding for proteins of 412 amino acids. These protein sequences were highly similar to Mariner transposases encoded by Soymarl and Osmarl ele- 
Table 3. Characterization of clones containing Mariner-like sequences. ORF, open reading frame.

\begin{tabular}{|c|c|c|c|c|c|c|c|}
\hline $\begin{array}{l}\text { Element } \\
\text { name }\end{array}$ & $\begin{array}{l}\text { Length } \\
\text { (bp) }\end{array}$ & $\mathrm{ORF}^{a}$ & $\begin{array}{l}\text { Clone } \\
\text { name }\end{array}$ & $\begin{array}{l}\text { Length } \\
\text { (bp) }\end{array}$ & $\begin{array}{l}\text { GenBank } \\
\text { accession }\end{array}$ & $\begin{array}{l}\text { Element } \\
\text { position }\end{array}$ & Notes \\
\hline Psmar-1A & 3204 & $\begin{array}{l}412 \text { aа } \\
\quad(872-2107)\end{array}$ & c752_part & 6339 & AY833549 & $916-4119$ & Full-length element. \\
\hline Psmar-1B & 3201 & $\begin{array}{l}412 \text { aa } \\
\quad(873-2108)\end{array}$ & c756_part & 5572 & AY833550 & $1231-4431$ & $\begin{array}{l}\text { Full-length element; } 99 \% \text { sequence similar- } \\
\text { ity to Psmar-1A. }\end{array}$ \\
\hline Psmar-2 & Unknown & $\sim 412 \mathrm{aa}^{b}$ & c771_3end & 4637 & AY833551 & $(2771)-4451$ & $\begin{array}{l}\text { Left TIR sequence not identified, right TIR } \\
\text { ends at } 4451 . \text { ORF contains mutations } \\
\text { generating frameshifts and stop codons. }\end{array}$ \\
\hline Psmar-3A & $\begin{array}{l}2205 \\
\quad \text { (part.) }\end{array}$ & $\begin{array}{l}327 \text { aа } \\
\quad(1222-2399)\end{array}$ & c775 & 2399 & AY833552 & 195-2399 & $\begin{array}{l}\text { Partial sequence ( } 3^{\prime} \text { truncated because of } \\
\text { the cloning). }\end{array}$ \\
\hline Psmar-3B & $\begin{array}{l}994 \\
\quad \text { (part.) }\end{array}$ & - & c716 & 2588 & AY833553 & $1595-2588$ & $\begin{array}{l}\text { Partial sequence ( } 3^{\prime} \text { truncated because of } \\
\text { the cloning). The element sequence has } \\
99 \% \text { similarity to Psmar-3A except for } \\
\text { an internal deletion of } 1215 \text { nucleotides } \\
\text { at the position } 2079 \text {. }\end{array}$ \\
\hline
\end{tabular}

${ }^{a}$ Open reading frame coding for putative transposase. The length of the deduced protein sequence and position of the ORF within the element (in parentheses) are given.

${ }^{b}$ Deduced length after correction of frameshift and stop codon mutations.

ments (Jarvik and Lark 1998; Tarchini et al. 2000; Feschotte and Wessler 2002) as well as by previously unknown elements identified in the genome of Medicago truncatula (Fig. 4B).

In addition to Psmar-1A and Psmar-1B, three other Mariner-like elements were identified (Table 3). One of them, Psmar-2, probably represents a partially decayed element, which because of the accumulation of numerous mutations or sequence rearrangements lost its left TIR. However, the right TIR still could be identified, as well as the remnants of the coding sequence, which displayed similarity to other elements. Following corrections of 4 mutations ( 2 stop codons and 2 frameshifts), the protein sequence encoded by this region could be deduced and aligned with other MLE transposases (Fig. 4B).

The other 2 elements, Psmar-3A and Psmar-3B, displayed 99\% mutual sequence similarity; but except for their coding regions, no homology to other elements was detected. Only the left TIR sequences were identified, as only partial sequences truncated at their right ends were obtained. Interestingly, these TIRs displayed much shorter homology to the pea Stowaway elements than Psmar-1; this homology was limited to the most terminal $9 \mathrm{bp}$ (or $12 \mathrm{bp}$ including 1 mismatch, Fig. 4A). As the sequence of Psmar-3B lacked 1215 bp because of internal deletion, only Psmar-3A was analyzed with respect to its coding capacity. An uninterrupted open reading frame was identified potentially coding for a protein with significant homology to those encoded by other Psmar elements (Fig. 4B).

\section{Discussion}

In the present study, we show that Stowaway MITEs are abundant in the pea genome, reaching $10^{3}-10^{4}$ copies per haploid genome. Although the molecular mechanisms of MITE amplification remain to be explained, a comparably high abundance of some MITE families in various species suggests that these mechanisms are a common phenomenon (Feschotte et al. 2002a; Casacuberta and Santiago 2003). For example, the Stowaway population in rice includes over 22000 elements, which can be classified into a number of subfamilies based on their sequence similarity (Feschotte et al. 2003). In this respect, it is interesting that although the sample of the pea Stowaway sequences reported here is rather limited, the variability within the sample is surprisingly low. This observation cannot be fully explained by probe homology bias during the screening, as the hybridization stringency was only moderate to allow for identification of partially divergent targets. Moreover, the average mutual similarity of the 3 elements identified previously using a principally different approach (computer analysis of sequence database entries Stow-Ps1, Stow-Ps2, and Stow-Ps3) is very close to that of the whole set of the pea elements (84\% versus $87 \%$ ).

Pea Stowaway elements have all the features typical for this group of transposons. They are short, AT-rich (73\% A + T), contain characteristic TIR sequences, and integrate into the dinucleotide TA (Bureau and Wessler 1994). Analysis of Stowaway elements present in the extensively sequenced rice genome revealed that they predominantly occur in the vicinity of potential gene sequences (Mao et al. 2000). This makes the Stowaway elements attractive for designing molecular markers based on insertional or inter-MITE polymorphisms (Casa et al. 2000; Chang et al. 2001) that could be targeted into gene-rich euchromatic regions. Our findings suggest that this approach is also feasible in pea, as at least part of the identified elements are located near potential gene sequences. Moreover, insertional polymorphism was already detected among various pea lines (subspecies and cultivars) for some of the elements (Fig. 3). On the other hand, some of the pea elements were found within repetitive (retroelement) sequences, which contrasts with the observation made about rice.

The successful identification of Mariner-like sequences in the pea genome is not surprising, as the presence of numerous subfamilies of MLE transposases was reported from a range of monocot and dicot species by using the PCR approach (Feschotte and Wessler 2002). In spite of these find- 
Fig. 4. (A) Comparison of the TIR sequences of pea Mariner-like and Stowaway elements. Left (L) and reverse complements of right (R) TIRs are shown for 2 subfamilies of MLEs (Psmar-1 and Psmar-3) and for the consensus sequence of Stowaway elements (Stow$P s$ ). In Psmar-1, the most terminal part of the right TIR is labeled R1, whereas the internally duplicated TIR region is labeled R2 (this sequence directly follows the R1 region). Identical nucleotides are indicated on black background. (B) Multiple alignment of predicted amino acid sequences of plant Mariner-like transposases. The sequences are derived from MLEs identified in pea (Psmar), soybean (Soymarl; Jarvik and Lark 1998), rice (Osmarl; Tarchini et al. 2000, Feschotte and Wessler 2002), and Medicago truncatula (Mt_AC137603; this is a newly identified element located at position 40833-44543 of the sequence AC137603.16). Position of the D.D39D motif is indicated with asterisks.

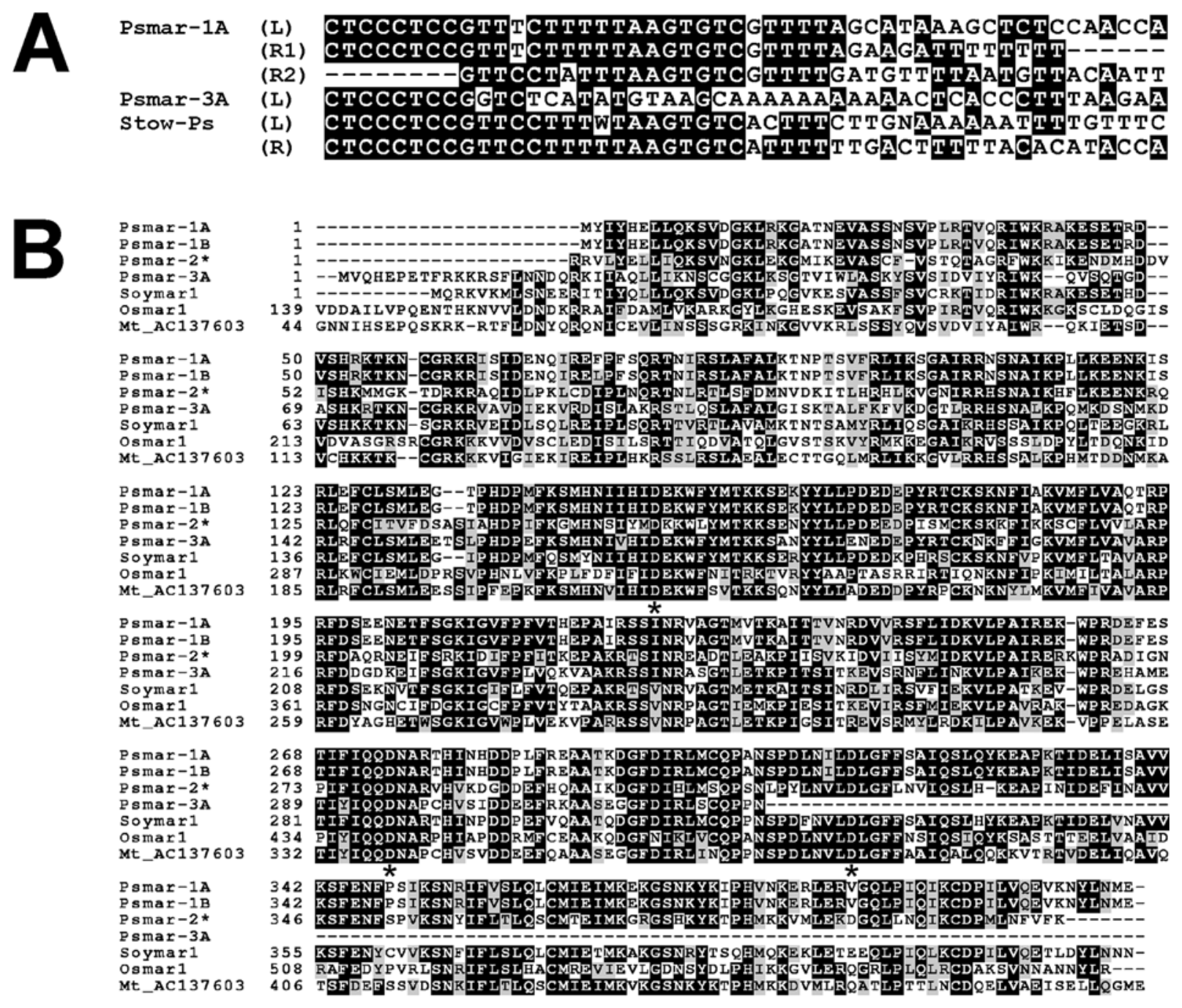

ings, up to now the only full-length elements have been reported for the soybean and rice genomes (Jarvik and Lark 1998; Tarchini et al. 2000; Feschotte and Wessler 2002). The assignment of the pea elements as Mariner-like transposons is strongly supported by their structure and the homology of their transposases, which are similar to those of Soymarl and Osmarl elements (Fig. 4B). In addition, the pea Psmar transposases include the D.D(39)D motif typical for plant MLEs (Feschotte and Wessler 2002).

The 5 sequenced pea elements represent 3 MLE subfamilies distinguished by their sequence similarity. We estimated that there are about 50 copies of MLEs; thus, the actual number of different subfamilies in the pea genome might be greater than the 3 reported here. A similar situation was reported for rice (Feschotte et al. 2003) and, based on the partial transposase sequences, also for other plant species (Feschotte and Wessler 2002). In addition, we made the same observation when searching for potential MLEs in genomic sequences of a model legume plant Medicago truncatula in which several distinct subfamilies sharing sequence similarity only within their TIRs and transposasecoding regions were identified (J. Macas and P. Neumann, unpublished data). Contrary to a large proportion of the previously reported plant transposase-coding sequences, which were disrupted by mutations creating frameshifts or stop codons (Feschotte and Wessler 2002; Feschotte et al. 2003), only 1 of the 7 partial or full-length transposase sequences identified in pea was disrupted by mutations. This suggests that a large fraction of pea MLEs may be capable of producing functional transposase and thus mediating their own mobility as well as the nonautonomous Stowaway elements. It has been proposed that sequence identity of TIRs is required for cross-mobilization of nonautonomous MITEs by their master elements (Feschotte et al. 2003). Thus, the most 
likely candidates for these master elements are the transposons of the Psmar-1 subfamily, as their homology to Stowaway MITEs extends over the whole TIRs (Fig. 4A). In contrast, the similarity of Psmar-3 TIRs to those of Stowaway and Psmar-1 is limited to the most terminal region.

The present data obtained from pea as the representative of the legume family (Fabaceae) complement the findings reported for rice and other (mainly grass) species. It was shown that the pea genome contains a relatively homogenous population of Stowaway MITEs in addition to several subfamilies of Mariner-like transposons that could potentially act as the master elements, providing functional transposase capable of mediating their mobility. This raises questions about the potentially ongoing transpositional activity of Stowaway elements in pea, which seems possible considering the presence of intact MLEs and the occurrence of insertional polymorphism of corresponding MITEs detected in different pea lines. Thus, the pea genome may represent a good model for investigating the biology and activity of Mariner-like and Stowaway elements in plants.

\section{Acknowledgements}

We thank Ms. H. Štěpančíková for excellent technical assistance and Dr. Robert Stupar for assistance in preparing the manuscript. We are also grateful to Western Regional Plant Introduction Station, Pullman, USA, and Plant Breeding Station at Borsov, Czech Republic, for providing the seeds of plants used in this study. This work was supported by grants GA521/00/0655 and GA521/03/0595 from the Grant Agency of the Czech Republic and by grant AV0Z50510513 from the Academy of Sciences of the Czech Republic.

\section{References}

Altschul, S.F., Madden, T.L., Schäffer, A.A., Zhang, J., Zhang, Z., Miller, W., et al. 1997. Gapped BLAST and PSI-BLAST: a new generation of protein database search programs. Nucleic Acids Res. 25: 3389-3402.

Baranyi, M., and Greilhuber, J. 1996. Flow cytometric and Feulgen densitometric analysis of genome size variation in Pisum. Theor. Appl. Genet. 92: 297-307.

Bennetzen, J.L. 2000. Transposable element contributions to plant gene and genome evolution. Plant Mol. Biol. 42: 251-269.

Bureau, T.E., and Wessler, S.R. 1992. Tourist: a large family of small inverted repeat elements frequently associated with maize genes. Plant Cell. 4: 1283-1294.

Bureau, T.E., and Wessler, S.R. 1994. Stowaway: a new family of inverted repeat elements associated with the genes of both monocotyledonous and dicotyledonous plants. Plant Cell. 6: 907-916.

Casa, A.M., Brouwer, C., Nagel, A., Wang, L.J., Zhang, Q., Kresovich, S., et al. 2000. The MITE family Heartbreaker (Hbr): molecular markers in maize. Proc. Natl. Acad. Sci. U.S.A. 97: $10083-10089$.

Casacuberta, J.M., and Santiago, N. 2003. Plant LTR-retrotransposons and MITEs: control of transposition and impact on the evolution of plant genes and genomes. Gene, 311: 1-11.

Chang, R.Y., O’Donoughue, L.S., and Bureau, T.E. 2001. InterMITE polymorphisms (IMP): a high throughput transposon-based genome mapping and fingerprinting approach. Theor. Appl. Genet. 102: 773-781.

Crooks, G.E., Hon, G., Chandonia, J.M., and Brenner S.E. 2004. WebLogo: a sequence logo generator. Genome Res. 14:1188-1190.
Dellaporta, S.L., Wood, J., and Hicks, J.B. 1983. A plant DNA minipreparation: version II. Plant Mol. Biol. Rep. 1: 19-21.

Feschotte, C., and Wessler, S.R. 2002. Mariner-like transposases are widespread and diverse in flowering plants. Proc. Natl. Acad. Sci. U.S.A. 99: 280-285.

Feschotte, C., Jiang, N., and Wessler, S.R. 2002a. Plant transposable elements: where genetics meets genomics. Nature Rev. Genet. 3: 329-341.

Feschotte, C., Zhang, X., and Wessler, S.R. 2002b. Miniature inverted-repeat transposable elements and their relationships to established DNA transposons. In Mobile DNA II. Edited by N.L. Craig, R. Craigie, M. Gellert, and A.M. Lambowitz. ASM Press, Washington, D.C. pp. 1147-1157.

Feschotte, C., Swamy, L., and Wessler, S.R. 2003. Genome-wide analysis of mariner-like transposable elements in rice reveals complex relationships with Stowaway miniature inverted repeat transposable elements (MITEs). Genetics, 163: 747-758.

Galun, E. 2003. Transposable elements. Kluwer Academic Publishers, Dordrecht, Netherlands.

Jarvik, T., and Lark, K.G. 1998. Characterization of Soymarl, a Mariner element in soybean. Genetics, 149: 1569-1574.

Kumar, A., Pearce, S.R., McLean, K., Harrison, G., Heslop-Harrison, J.S., Waugh, R., et al. 1997. The Ty1-copia group of retrotransposons in plants: genomic organisation, evolution, and use as molecular markers. Genetica (The Hague), 100: 205-217.

Macas, J., Neumann, P., and Požárková, D. 2003. Zaba: a novel miniature transposable element present in genomes of legume plants. Mol. Genet. Genomics. 269(5): 624-631.

Mao, L., Wood, T.C., Yu, Y.S., Budiman, M.A., Tomkins, J., Woo, S.S., et al. 2000. Rice transposable elements: a survey of 73000 sequence-tagged- connectors. Genome Res. 10: 982-990.

Neumann, P., Nouzová, M., and Macas, J. 2001. Molecular and cytogenetic analysis of repetitive DNA in pea (Pisum sativum L.). Genome, 44: 716-728.

Pearson, W.R., and Lipman, D.J. 1988. Improved tools for biological sequence comparison. Proc. Natl. Acad. Sci. U.S.A. 85: 2444-2448.

Sanger, F., Nicklen, D., and Coulson, A.R. 1977. DNA sequencing with chain terminating inhibitors. Proc. Natl. Acad. Sci. U.S.A. 74: 5463-5467.

SanMiguel, P., and Bennetzen, J.L. 1998. Evidence that a recent increase in maize genome size was caused by the massive amplification of intergene retrotransposons. Ann. Bot. (Lond). 82: 37-44.

Schneider, T.D., and Stephens, R.M. 1990. Sequence logos: a new way to display consensus sequences. Nucleic Acids Res. 18: 6097-6100.

Sonnhammer, E.L.L., and Durbin, R. 1995. A dot-matrix program with dynamic threshold control suited for genomic DNA and protein sequence analysis. Gene, 167: GC1-10.

Staden, R. 1996. The Staden sequence analysis package. Mol. Biotechnol. 5: 233-241.

Tarchini, R., Biddle, P., Wineland, R., Tingey, S., and Rafalski, A. 2000. The complete sequence of $340 \mathrm{~kb}$ of DNA around the rice Adh1-Adh2 region reveals interrupted colinearity with maize chromosome 4. Plant Cell. 12: 381-391.

Thompson, J.D., Higgins, D.G., and Gibson, T.J. 1994. CLUSTAL W: improving the sensitivity of progressive multiple sequence alignment through sequence weighting, position-specific gap penalties and weight matrix choice. Nucleic Acids Res. 22: 4673-4680.

Zhang, Q., Arbuckle, J., and Wessler, S.R. 2000. Recent, extensive, and preferential insertion of members of the miniature invertedrepeat transposable element family Heartbreaker into genic regions of maize. Proc. Natl. Acad. Sci. U.S.A. 97: 1160-1165. 